\title{
Future directions for supporting parents with a mental illness: commentary on Schrank et al. (2015)
}

\author{
Katy Kaplan ${ }^{1,2} \cdot$ Mark S. Salzer $^{2}$
}

Received: 27 January 2016/ Accepted: 23 March 2016/Published online: 29 April 2016

(C) Springer-Verlag Berlin Heidelberg 2016

When it comes to understanding anything involving the topic of parenting with a mental illness, one must keep in mind that we are only a few decades removed from the international phenomenon of sterilization of those who were deemed socially or mentally unfit. The origins of sterilization emerged from the eugenics movement- "to make better breeding" that inspired and propelled studies that sought to show the danger of 'defectives' or 'feebleminded' procreating [1]. In the United States, a model sterilization law was widely implemented in many states and upheld by the Supreme Court in Buck v. Bell-a decision that, to this day has yet to be overturned, setting the precedent for over 65,000 cases of forced sterilization in the United States [2]. While sterilization is no longer publicly viewed as acceptable, other limitations on parental rights still exist. For example, 35 states include a mental disability as grounds for termination of parental rights [3] and some states include parents with a mental illness, in a category with those who have abandoned, tortured, sexually abused, or murdered their children, where reasonable efforts to re-unify them with their children is no longer required by the state [4].

It is from this important perspective that the Schrank et al.'s (2015) review should be understood, especially in terms of the quality of the research that is currently

This comment refers to the article available at doi:10.1007/s00127015-1069-3

Katy Kaplan

katy.kaplan@temple.edu; katy.kaplan@phila.gov

1 Community Behavioral Health, 801 Market Street, 11th Fl., Philadelphia, PA 19107, USA

2 TU Collaborative On Community Inclusion, Temple University, 1700 North Broad Street, Suites 304 and 313, Philadelphia, PA 19122, USA available around the world, and, the gaps in research directions that have yet to be taken. In particular, while obliquely discussed by Schrank and colleagues (2015), it is believed that greater attention to the context in which many individuals with serious mental illnesses live their lives is paramount. This includes the need to consider the role of poverty, and multiple environmental and health stressors that are clearly identified as critical factors in parenting, for anyone. Moreover, greater attention needs to be paid to possible prejudice and discrimination that can affect outcomes as well. These parents are arguably subject to mental illness exceptionalism, the process where everything in the life of someone with a mental illness is viewed through the lens of the mental illness rather than other factors that commonly affect people with mental illnesses.

As Schrank et al. (2015) point out, there has been an increasing recognition that people with serious mental illnesses are as likely, and possibly more likely, to be parents, and that there has been a dramatic increase in the number of intervention studies that have been conducted in this area. Two-thirds of the studies included in this review were published after 2000. Unfortunately, much of this research, while making a substantial contribution in this pressing public health area, uses less rigorous methods that undermine a high degree of confidence in the validity of the findings. Not surprisingly, Schrank et al. (2015) conclude that while findings seem promising, it is glaringly apparent that more rigorous research is needed. A cursory examination of the literature on parenting with a mental illness suggests that a good deal of the research is either unfunded or involved minimal funding, which might partly explain the less rigorous designs that are used. Despite the lack of substantial and consistent funding, there are a number of investigators around the world who are committed to this topic, including a fledgling bi-annual conference on 
parenting. More grant funding will be needed in this area to increase the use of more rigorous research designs.

Schrank et al. (2015) also make several additional sound recommendations for next steps. They note key needs in terms of intervention development, including interventions that target non-custodial parents and those that are inclusive of older children such as adolescents and teens. Research that examines child outcomes should go beyond parental reports/assessments and either engage the child directly or utilize secondary data such as child welfare data, school reports and mental health services data. Given the lack of a resource-oriented approach, future research should also examine parental resiliency factors that result in positive parent and child outcomes, to identify essential intervention components. This could be useful for informing programs specifically designed for parents with a SMI or mainstream parenting interventions that are inclusive of parents with a SMI.

Schrank and colleagues (2015) touch on another critical issue-whether there is a need for special programs or diagnosis specific interventions for these families. Indeed, there is also a need for research that examines the extent to which parenting issues among persons with serious mental illnesses are unique (e.g., by symptom/diagnosis, acuity, disclosure) versus other factors that they have a high likelihood of experiencing, such as poverty and stress. These latter factors are known contributors to parenting problems in the general population, for which there are already some welldeveloped evidence-based interventions.

Luciano et al. (2014) found that parents with a SMI, compared to parents without a SMI, were less economically stable and more likely to fall below the poverty line [5]. Poverty and unemployment are two major issues associated with child welfare involvement and both generate additional risks such as housing instability, inaccessible healthcare, and community violence [6]. Poverty can also result in greater exposure to detection of problems, as poorer families are more likely to receive intrusive social services, and are therefore, more likely than wealthier families to be identified by child welfare authorities or mandated reporters. It is plausible that poverty is the primary causal factor, rather than the mental illness itself, that results in the problems affecting these families. A similar argument has been made for why people with mental illnesses experience higher rates of homelessness, criminal justice involvement, and other social problems [7]. Such contextualizing research is needed to combat mental illness exceptionalism which we mentioned earlier.

In fact, this exceptionalism may make parents with a SMI, more critical of their own parenting and lead them to erroneously attribute a common parenting struggle to an illness based deficit [8]. This is in line with Schrank et al.'s (2015) criticism of the lack of a resource-oriented approach to understanding parenting, whereby parenting is viewed as a positive motivating factor for treatment and source of stability [9]. A majority of women with a SMI get a sense of meaning and purpose from their parent-child relationship and note their desire to take good care of their children. More research is needed on parenting outcomes as a facilitator of well-being, quality of life, symptom reduction, and recovery. Research should examine how providers are working with individuals who are parents, especially focusing on whether their role as a parent is included in treatment planning for non-coercive purposes. For example, Fox (2009) reported how her treatment providers missed the opportunity to utilize her role as a mother, as a motivator for mental health recovery [9].

One final consideration not discussed by Schrank and colleagues (2015) is the need for intervention outside the mental health service system. Families living with parental mental illnesses may come into contact with numerous service systems including education, social services, child welfare, and the courts. Therefore, outreach and trainings of professionals in these systems are crucial. Stigma and discrimination of parents with a SMI persist. Women with disabilities continue to confront coercive tactics designed to encourage abortions or sterilization, the latter being especially true among women with intellectual or psychiatric disabilities [2]. Additionally, legislative and judicial systems continue to limit the parenting rights of individuals with a SMI. When parents come under the scrutiny of the judicial system, they once again come up against negative beliefs grounded in outdated views regarding individuals with mental illnesses. Judges and even attorneys representing parents with mental illnesses, often speciously interpret the diagnosis as an indicator of dangerousness [10].

Schrank et al.'s (2015) review is an evidence that there is a growing recognition of the need to support families living with parental mental health challenges. While a great deal more is needed in terms of research, services and policy to achieve positive outcomes for parents and their children, this review provides an initial roadmap for next steps.

Acknowledgement The contents of this publication were developed under a grant from the Department of Education, National Institute on Disability, Independent Living, and Rehabilitation Research grant number H133B10014 (Salzer, PI). However, those contents do not necessarily represent the policy of the Department of Education, and you should not assume endorsement by the Federal Government.

\section{References}

1. Pfeiffer D (1994) Eugenics and disability discrimination. Disabil Soc 9(4):481-499

2. Powell R (2014) Can parents lose custody simply because they are disabled? Am Bar Assoc 31(2):14-17 
3. NCD (2012) Rocking the cradle: ensuring the rights of parents with disabilities and their children. In: Powell R, ed. National Council on Disability, Washington

4. Friesen B, Nicholson J, Kaplan K, Solomon P (2009) Parents with a mental illness and implementation of the Adoption and Safe Families Act, Monograph on ASFA. Center for the Study of Social Policy and The Urban Institute, Washington

5. Luciano A, Nicholson J, Meara E (2014) The economic status of parents with serious mental illness in the United States. Psychiatr Rehabil J 37(3):242-250

6. Brown J, Cohen P, Johnson JG, Salzinger S (1998) A longitudinal analysis of risk factors for child maltreatment: findings of a 17-year prospective study of officially recorded and self-reported child abuse and neglect. Child Abuse Negl 22(11):1065-1078
7. Draine J, Salzer MS, Culhane DP, Hadley TR (2002) Role of social disadvantage in crime, joblessness, and homeless among persons with serious mental illness. Psychiatr Serv 53(5):565-573

8. Nicholson J, Sweeney EM, Geller JL (1998) Mothers with mental illness: I. The competing demands of parenting and living with mental illness. Psychiatr Serv 49(5):635-642

9. Fox L (2009) Second chance at motherhood. Psychiatr Rehabil J $33(2): 150-152$

10. Kundra LB, Alexander LB (2009) Termination of parental rights proceedings: legal considerations and practical strategies for parents with psychiatric disabilities and the practitioners who serve them. Psychiatr Rehabil J 33(2):142-149 